\title{
$\underline{\mathbf{P}-117}$
}

\section{Hopeanolin and other Resveratrol Oligomers from the Twigs of Shoreaacuminata: Antioxidant Propertiesand Chemotaxonomic Significance}

\author{
Norhayati Muhammad ${ }^{1,2, *}$, Laily B. Din ${ }^{2}$, Nazlina Ibrahim $^{3}$, Zuriati Zakaria ${ }^{2}$ and Wan A. Yaacob ${ }^{2}$ \\ ${ }^{1}$ Institute of Teacher Education, Ministry of Education, Blok 2200, JalanPersiaranApec, Cyber 6, 63000 Cyberjaya, \\ Selangor D.E., Malaysia; ${ }^{2}$ School of Chemical Sciences and Food Technology, Faculty of Science and Technology, \\ UniversitiKebangsaanMalaysia, UKMBangi 43600,Selangor D.E., Malaysia; ${ }^{3}$ School of Biosciences and Biotechnology, \\ Faculty of Science and Technology, UniversitiKebangsaanMalaysia, UKMBangi 43600, Selangor D.E., Malaysia; \\ E-mail: norhayatimuhammad@gmail.com
}

(-)-Hopeanolin (1) [1] was isolated from the acetone extract of the twigs of Shoreaacuminata (Dipterocarpaceae), together with four resveratrol oligomers namely (-)-laevifonol [2], (-)- $\alpha$-viniferin [3], (+)-vaticanol B [4] and (-)-hopeaphenol. The structure of these compounds were established based on spectroscopic evidence, including UV, IR, NMR and mass spectra. Compound 1 showed the potent ability to protect $\beta$-carotene bleaching by linoleic acid and also to scavenge DPPH radicals with $\mathrm{IC}_{50} \mathrm{~s} 0.18$ and $6.58 \mathrm{mM}$ respectively. The presence of compound $\mathbf{1}$ and the other four resveratrol oligomers in this species have great chemotaxonomic significance on the relationship between Shorea and other genera of Dipterocarpaceae especially Hopea.

\section{REFERENCES}

[1] Ge HM, Huang B, Tan SH, et al. Bioactive oligostilbenoids from the stem bark of Hopea exalata. J Nat Prod 2006; 69: 1800-2.

[2] Hirano Y, Kondo R, Sakai K.. 5A-Reductase inhibitory tannin-related compounds isolated from Shorea laeviforia. J Wood Sci 2003; 49: 339-43

[3] Muhtadi, et al. <Title> ProceedingIndonesian Symposium of Science \& Technology on Chemistry 2006; 45-51.

[4] Tanaka T, Ito T, Nakaya K. A novel resveratrol hexamer isolated from Vatica rassak. Tetrahedron Lett 2000; 41: 7929-32. 